\title{
Combination of ALA-induced fluorescence-guided resection and intraoperative open photodynamic therapy for recurrent glioblastoma: case series on a promising dual strategy for local tumor control
}

\author{
*Stephanie Schipmann, MD, ${ }^{1}$ Michael Müther, MD, MSc," Louise Stögbauer, MD,1 \\ Sebastian Zimmer, MD, ${ }^{2}$ Benjamin Brokinkel, MD, ${ }^{1}$ Markus Holling, MD, ${ }^{1}$ Oliver Grauer, MD, PhD, ${ }^{3}$ \\ Eric Suero Molina, MD, MBA, ${ }^{1}$ Nils Warneke, MD, ${ }^{1}$ and Walter Stummer, MD ${ }^{1}$ \\ ${ }^{1}$ Department of Neurosurgery, ${ }^{2}$ Institute of Radiology, and ${ }^{3}$ Department of Neurology, University Hospital Münster, Germany
}

\begin{abstract}
OBJECTIVE High-grade glioma (HGG) prognosis remains dismal, with inevitable, mostly local recurrence. Regimens for improving local tumor control are therefore needed. Photodynamic therapy (PDT) using porfimer sodium has been investigated but was abandoned due to side effects and lack of survival benefits. Intracellular porphyrins induced by 5-aminolevulinic acid (5-ALA) are approved for fluorescence-guided resections (FGRs), but are also photosensitizers. Activated by light, they generate reactive oxygen species with resultant cytotoxicity. The authors present a combined approach of 5-ALA FGR and PDT.
\end{abstract}

METHODS After 5-ALA FGR in recurrent HGG, laser diffusors were strategically positioned inside the resection cavity. PDT was applied for 60 minutes $(635 \mathrm{~nm}, 200 \mathrm{~mW} / \mathrm{cm}$ diffusor, for 1 hour) under continuous irrigation for maintaining optical clarity and ventilation with 100\% oxygen. MRI was performed at 24 hours, 14 days, and every 3 months after surgery, including diffusion tensor imaging and apparent diffusion coefficient maps.

RESULTS Twenty patients were treated. One surgical site infection after treatment was noted at 6 months as the only adverse event. MRI revealed cytotoxic edema along resection margins in $16(80 \%)$ of 20 cases, mostly annular around the cavity, corresponding to prior laser diffusor locations (mean volume $3.3 \mathrm{~cm}^{3}$ ). Edema appeared selective for infiltrated tissue or nonresected enhancing tumor. At the 14-day follow-up, enhancement developed in former regions of edema, in some cases vanishing after $4-5$ months. Median progression-free survival (PFS) was 6 months $(95 \% \mathrm{Cl}$ 4.8-7.2 months).

CONCLUSIONS Combined 5-ALA FGR and PDT provides an innovative and safe method of local tumor control resulting in promising PFS. Further prospective studies are warranted to evaluate long-term therapeutic effects.

https://thejns.org/doi/abs/10.3171/2019.11.JNS192443

KEYWORDS protoporphyrin IX; 5-ALA; photosensitizing agents; photochemotherapy; photodynamic therapy; glioma; oncology

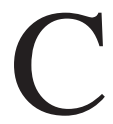

URRENT first-line therapy for high-grade gliomas (HGGs) comprises maximal safe resection of enhancing tumor followed by adjuvant radiation and chemotherapy. ${ }^{34}$ Notably, recurrence usually occurs at the margin of the resection cavity, ${ }^{38}$ suggesting that selective cytotoxic local therapy of marginal infiltrating tumor might be of value.
Currently, there are no standard-of-care regimens for the management of tumor relapse, and the overall level of evidence for possible interventions is low. Frequently, repeat resections are followed by alternate chemotherapy regimens or experimental immune-modulating therapies, either with or without re-irradiation. Several trials of novel approaches have been performed for recurrent HGGs, so

\footnotetext{
ABBREVIATIONS 5-ALA = 5-aminolevulinic acid; $A A=$ anaplastic astrocytoma; $A D C=$ apparent diffusion coefficient; $A O=$ anaplastic oligodendroglioma; $C E=$ contrast enhancement; CRET = complete resection of enhancing tumor; DWI = diffusion-weighted imaging; EOR = extent of resection; FGR = fluorescence-guided resection; GBM = glioblastoma; $\mathrm{HGG}$ = high-grade glioma; $\mathrm{PDT}$ = interstitial PDT; MEP = motor-evoked potential; oPDT = open PDT; OS = overall survival; $\mathrm{PDT}$ = photodynamic therapy; PFS = progression-free survival; PPIX = protoporphyrin IX; RANO = Response Assessment in Neurooncology; STR = subtotal resection. SUBMITTED September 25, 2019. ACCEPTED November 25, 2019.
} INCLUDE WHEN CITING Published online January 24, 2020; DOI: 10.3171/2019.11.JNS192443.

* S.S., M.M., N.W., and W.S. contributed equally to this work. 
far showing only limited response. ${ }^{7,10}$ Therefore, there is an ongoing, unmet need for therapeutic options for improving local tumor control.

One possible approach that has been explored in the past for local tumor control, mainly by Muller and Wilson, is photodynamic therapy (PDT) using photosensitizers such as hematoporphyrin derivative (porfimer sodium) in patients operated on for HGG. No survival benefit was observed in a randomized controlled phase III study. ${ }^{19,20}$ With this technique, patients were first subjected to debulking surgery. After intravenous application of porfimer sodium, a compound of purported affinity to HGG, resection cavities were filled with rubber balloons containing fat emulsion (Intralipid) as a medium for diffusing the laser light from within the balloon. ${ }^{19}$ Possibly due to the limited selectivity of porfimer sodium, the rate of side effects was high with severe and long-lasting skin sensitization and potential accidental damage to normal brain tissues. ${ }^{1,19,29}$

Currently, 5-aminolevulinic acid (5-ALA) is approved for fluorescence-guided resections (FGRs) helping to improve the extent of resection (EOR) for HGG..$^{12,30} 5$-ALA is taken up by tumor cells and selectively metabolized to protoporphyrin IX (PPIX), a strongly fluorescing precursor of heme, which remains confined to HGG cells. This phenomenon results in selective tumor cell fluorescence that can be visualized by using a specially equipped surgical microscope ${ }^{31}$ Apart from their strong fluorescence, induced endogenous porphyrins such as PPIX are strong photosensitizers. ${ }^{15,21}$ Consequently, besides being useful for improving EOR, 5-ALA might be used as a photosensitizer for PDT with the profound advantage over traditional photosensitizers, such as porfimer sodium, that no PPIX is in blood nor in peritumoral edema. To this end, promising results have been reported in several smaller studies..$^{2,14,28}$

PDT is based on a photochemical reaction induced by activation of sensitizer by light. ${ }^{6}$ After PPIX is excited with a 635-nm laser light, reactive oxygen species and free radical production are generated, ${ }^{11}$ leading to direct cytotoxic effects on tumor cells, destruction of vasculature, and induction of immune response. ${ }^{6,27}$ PDT has been applied using stereotaxy for introducing light diffusors into deep-seated lesions, a concept titled interstitial PDT (iPDT), with a prospective randomized trial currently in preparation. ${ }^{2,25,28}$ However, only small volumes can be covered by this technique and complex tumor architectures cannot be accounted for.

The concept of open PDT (oPDT) after resection is not new, however, here we introduce a novel mode of application. We hypothesize that in patients with recurrent HGG a combination of 5-ALA FGR and oPDT is a promising strategy for local tumor control, targeting residual, nonresectable, visibly fluorescent tumor, but also residual nonvisibly infiltrating fluorescent cells, which can be detected by spectrography. ${ }^{33,36}$ The objective of this study was to analyze the safety and efficacy of FGR with oPDT in a case series of patients treated at our center.

\section{Methods \\ Ethical Approval}

Open PDT was used on a compassionate use basis and decided on by an interdisciplinary neurooncological board in case-by-case discussions. All patients were informed about the experimental character of this type of surgical therapy and provided informed consent. The present collection of patient data was not from a planned, prospective study and retrospective data were intensely discussed with the local ethical committee given the number of patients we finally compiled. The study was approved.

\section{Study Design and Setting}

We report a case series of all patients treated with oPDT after repeat FGR for recurrent HGG at a single academic neurooncological center between October 2018 and May 2019. All patients were treated according to the procedures mentioned below. We observed patients for safety (any adverse events) and efficacy (cytotoxic edema surrounding the resection cavity, progression-free survival [PFS], and overall survival [OS]).

\section{Study Collective}

All patients surgically treated for recurrent HGG after introduction of the protocol mentioned below were found eligible. The inclusion criterion was 5-ALA FGR and consecutive oPDT during the same operative approach.

\section{FGR and OPDT Protocol}

5-ALA (Gliolan, Medac) was administered at a dosage of $20 \mathrm{mg} / \mathrm{kg}$ body weight 4 hours prior to induction of anesthesia. A standard craniotomy was performed. Neuronavigation was used for planning the surgical approach and identification of recurrent tumor tissue. Functional MRI and fiber-tracking studies were obtained as necessary, as well as methods of intraoperative mapping and monitoring, including awake craniotomies for language mapping. In each case, maximal safe resection of fluorescent tissue was attempted, aimed at complete resection of fluorescent tumor. Resection was performed using a cavitron ultrasonic surgical aspirator (CUSA Clarity, Integra Life Sciences). The surgical microscope (Zeiss, Pentero 900) enabled visualization of porphyrin fluorescence using the BLUE400 filter. Histopathology was confirmed by intraoperative frozen sections. Once there was no residually visible fluorescence or only tumor-infiltrated, visibly fluorescing eloquent areas were left, 1-4 cylindrical laser diffusers (Biolitec), depending on the size and architecture of the resection cavity, were inserted into the cavity and fixed to a retractor system. Possible diffusor lengths were 10-30 mm. Neuronavigation was used to confirm the position of the laser diffusers and enable a postoperative correlation with postoperative imaging. PDT was applied for 60 minutes $(635 \mathrm{~nm}, 200 \mathrm{~mW} / \mathrm{cm}$ diffusor) using a highpower laser with up to 8 ports for diffusors (Modulight ML7710, Tampere). Cavities were continuously irrigated with Ringer's lactate solution to maintain clarity of optical media in the cavity. The patient was ventilated with $100 \%$ oxygen during therapy. Four primary neurooncological surgeons (N.W., B.B., M.H., W.S.), including the senior authors (N.W., W.S.), performed the procedures. All resections were finalized by one of the senior authors (W.S.). Preoperatively, patients received $4 \mathrm{mg}$ of dexamethasone 
A

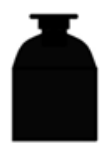

$20 \mathrm{mg} / \mathrm{kg}$ body weight 5-ALA

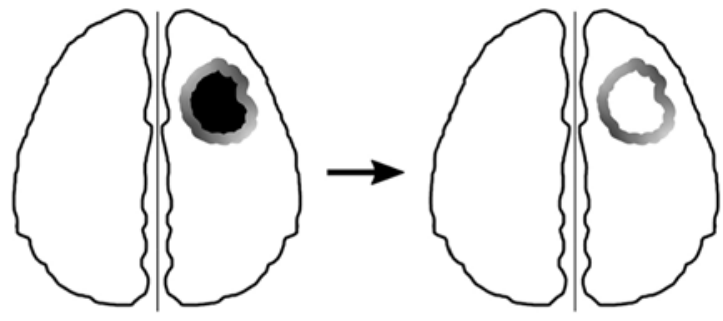

State-of-the-art fluorescence-guided microsurgical resection

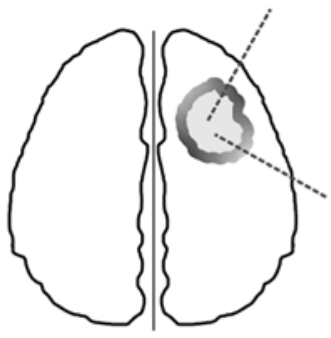

Open photodynamic therapy of resection cavity

- number of diffusors according to cavity architecture - constant irrigation of cavity

- ventilation at FiO2 1.0

- laser setting: $635 \mathrm{~nm}$ wave length, $200 \mathrm{~mW} / \mathrm{cm}^{2}, 1 \mathrm{hr}$
B

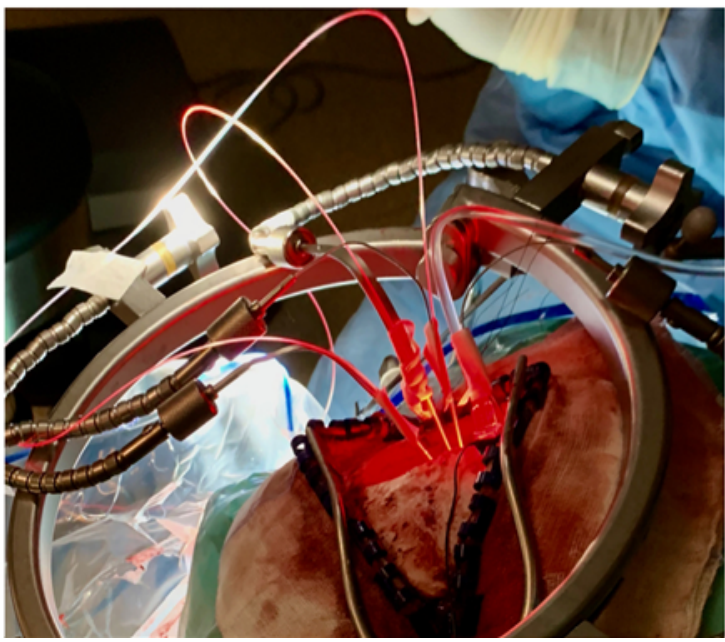

FIG. 1. A: Overview of the comprehensive FGR/oPDT protocol. B: Photograph of oPDT with 3 diffusors in situ. Figure is available in color online only.
3 times a day for a duration of 3 days, which was tapered consecutively. See Fig. 1 for a comprehensive FGR/oPDT protocol overview.

\section{MRI Protocol}

Standard preoperative and early postoperative (within 48 hours after surgery) 1.5 -T MR images were obtained from every patient. An additional postoperative MRI was performed at a time point 2 weeks after surgery to analyze changes in diffusion imaging. The following sequences underwent further qualitative and quantitative volumetric analysis: T1-weighted, T1-weighted contrast-enhanced, FLAIR, diffusion-weighted imaging (DWI), and apparent diffusion coefficient (ADC) sequences. Images were segmented and volumes were analyzed using an established semiautomatic technique (Brainlab Elements, Brainlab). We defined the volume of cytotoxic edema in the early postoperative MRI as an oPDT efficacy measure, showing a new true diffusion restriction as matching signal volumes in DWI and ADC map without contrast enhancement (CE). We then compared the areas of residual tumor and the infiltrating zone as seen on T1-weighted and T1weighted Gd-enhanced images with the extension of the cytotoxic edema. Residual enhancing tumor volumes of less than $0.175 \mathrm{~cm}^{3}$ were considered to represent complete resections of enhancing tumor (CRETs) in accordance with previous publications. All other cases were classified as subtotal resection (STR).

Routine follow-up MRI was performed every 3 months and assessed according to the modified Response Assessment in Neurooncology (RANO) criteria. ${ }^{40}$

\section{Data Analyses}

The IBM SPSS Statistics package (version 25.0, IBM Corp.) was used for statistical analyses. Data were analyzed by standard statistics, using absolute and relative frequencies for categorical variables and median and standard deviation for continuous variables. Time-to-event analyses were performed using Kaplan-Meier curves and the logrank test. PFS defines the time from surgery reported in this study (FGR and oPDT) until progression according to modified RANO criteria or death. OS was defined as time from oPDT to death. A probability value $<0.05$ was considered statistically significant. All reported $\mathrm{p}$ values are 2-sided.

\section{Results}

Over an 8-month period, 20 (38\%) of a total of 52 surgically treated patients for recurrent HGG $(65 \%$ males and $35 \%$ females, median age 54 years, range $21-81$ years) were treated with FGR and oPDT. Most patients suffered 
from glioblastoma (GBM; $n=17,85 \%)$, whereas 1 each $(5 \%)$ was treated for gliosarcoma, anaplastic oligodendroglioma (AO), or anaplastic astrocytoma (AA), respectively. In 1 patient (case 15) with a previous diagnosis of GBM, intraoperative frozen sections indicated viable tumor, yet final histopathological analysis revealed radiation necrosis. The median duration between initial diagnosis and tumor recurrence leading to repeat resection and open PDT was 15 months (range 2-144 months). Fifty percent ( $\mathrm{n}=$ 10) of patients were operated on due to a recurrent lesion in eloquent or near-eloquent areas, requiring combined motor-evoked potential (MEP) monitoring and subcortical dynamic mapping of the corticospinal tract in 8 cases and awake craniotomy and cortical Penfield mapping for speech in 2 cases. For PDT, 1 or 2 diffusors were used in $45 \%$ each, and in 2 cases (10\%) 3 diffusors were applied. Further patient characteristics, information regarding previous oncological therapy, and surgical details are summarized in Table 1.

\section{Patient Safety}

No adverse events or new posttherapeutic neurological deficits were observed in the collective series. One patient developed a surgical site infection with the need for surgical revision 6 months after FGR and oPDT (case 7).

\section{MRI Efficacy Analysis}

Complete resection of $\mathrm{CE}$ from an MRI perspective was achieved in 9 cases (45\%). FGR was complete in 8 cases $(40 \%$, Table 2). Early postoperative MRI revealed cytotoxic edema along the margin of the resection cavity in $16(80 \%)$ of 20 cases. Edema was mainly annular around the resection cavity, corresponding to the location of laser diffusors with a mean volume of $3.3 \mathrm{~cm}^{3}$, appearing to be selective for residual tumor, either from the infiltrating zone or nonresectable contrast-enhanced tumor. The mean perpendicular penetration depth on diffusion imaging was $9.1 \pm 2.96 \mathrm{~mm}$ (range 4.1-13.7 mm). The ADC normalized after 2 weeks, still showing a DWI signal, as a result of changes in T2-weighted sequences. Follow-up MRI after 14 days demonstrated posttherapeutic blood-brain barrier breakdown with $\mathrm{CE}$ of the former region of cytotoxic edema. Further follow-up MRI showed the initial progress of $\mathrm{CE}$ to regress and in some cases vanish after approximately 4-5 months. This phenomenon could be observed in most patients and is exemplarily demonstrated in Fig. 2.

\section{Survival Analysis}

In all, 12 patients showed tumor progression during follow-up. Tumor progression was found to be at the site of the PDT in 9 cases (75\%). In the remaining 3 cases (25\%) patients suffered from distant progression without showing any signs of local tumor growth after PDT. Median PFS in the entire cohort was 6 months (95\% CI 4.8-7.2 months; Fig. 3A). Patients who were operated on due to their first tumor recurrence did not show any statistically significant differences in PFS $(p=0.261)$ compared with those with surgery for a second tumor recurrence.

The same findings applied when comparing subgroups of patients with primary and secondary GBM $(p=0.176)$. Similarly, comparing EORs (CRET vs STR) from MRI and resection of visible fluorescence did not reveal any differences regarding patient PFS $(\mathrm{p}=0.446$ and $\mathrm{p}=0.316$, respectively). OS at 6 months was $75 \%$. Four tumor-related deaths were registered during the median observation period of 5 months.

\section{Discussion}

In this study we evaluated the feasibility of adding 5-ALA oPDT to FGR for recurrent HGG using 5-ALA in the same procedure. 5-ALA is the only compound approved for FGR, but also carries potential as a photosensitizer and is thus of theranostic use.

So far, there is no management consensus for recurrent HGG. Available nonrandomized studies indicate that patients appear to benefit from repeat resection. ${ }^{4,24}$ PDT is based on the destruction of malignant cells caused by light-induced activation of a photosensitizer selectively accumulating in tumor cells. ${ }^{27}$ It is well known that the majority of HGGs recur within $2 \mathrm{~cm}$ of the initial tumor margin..$^{38}$ Therefore, methods resulting in selective tumor cell death in infiltrating margins of HGG are of potential value.

The concept of open PDT is not new and has been explored in the past using first-generation photosensitizers, such as porfimer sodium. After intravenous application, porfimer sodium circulates in the blood and is extravasated across the disrupted blood-brain barrier, resulting in increased local concentrations in tumor tissue. However, due to severe side effects and lack of tumor specificity, this technique was abandoned. ${ }^{1,29}$

Our dual approach, combining 5-ALA FGR of recurrent tumor, the photosensitizing properties of 5-ALA-derived PPIX for intraoperative oPDT, and a novel multiport high-power laser, offers a promising strategy for local tumor control. Using FGR in combination with intraoperative neuromonitoring in cases of lesions within or next to eloquent areas, we could achieve CRET from an MRI perspective in 50\%, and in $30 \%$ according to fluorescence criteria. This rate of complete resections is consistent with the data from a recently published multicenter study on repeat resection of recurrent $\mathrm{GBM}^{24}$ and considerably higher than in other studies. ${ }^{4}$

\section{Effects of PDT}

PDT leads to an activation of cell death, resulting in necrosis, apoptosis, destruction of tumor microvasculature, and induction of immune responses., ${ }^{9,16,27}$ Possible longterm effects of PDT are based on the immunomodulatory effect, favoring the generation of a systemic antitumor immunity. ${ }^{17}$

Target tissue of oPDT is not only residual fluorescent tissue that was left behind for functional reasons. In cases of complete resection of fluorescent tissue, residual tumor burden has been shown to refer to cell density lower than $12 \%$. Tumor cellularity has been demonstrated to correlate with spectrometrically determined fluorescence intensity. Therefore, this tissue in tumor margins not visible through the microscope may still be addressed by oPDT. ${ }^{32}$ 
TABLE 1. Patient characteristics and oncological and surgical details

\begin{tabular}{|c|c|c|c|c|c|c|c|}
\hline $\begin{array}{l}\text { Case } \\
\text { No. }\end{array}$ & $\begin{array}{l}\text { Age (yrs) } \\
\text { Sex }\end{array}$ & $D x$ & Location* & $\begin{array}{l}\text { Mos Since } \\
\text { Initial Dx }\end{array}$ & Previous Oncological Treatment & Surgery & $\begin{array}{l}\text { No. of } \\
\text { Diffusors }\end{array}$ \\
\hline 1 & $52, \mathrm{M}$ & $\begin{array}{l}\text { GBM, IDH wt, } \\
\text { MGMT nm }\end{array}$ & $\mathrm{RP}$ & 11 & $\begin{array}{l}\text { Initial surgery CR; concomitant RT/chemo (60 Gy) + TMZ; } \\
\text { TMZ (5/28)† } 6 \text { cycles }\end{array}$ & $\begin{array}{l}\text { STR, IOM } \\
\text { (MEP) }\end{array}$ & 1 \\
\hline 2 & $41, \mathrm{M}$ & $\begin{array}{l}\text { GBM, IDH wt, } \\
\text { MGMT nm }\end{array}$ & LF & 12 & $\begin{array}{l}\text { Initial surgery CR; concomitant RT/chemo (60 Gy) + TMZ } \\
\text { + CCNU (CeTeG protocol); TMZ + CCNU } 6 \text { cycles; TTF } \\
\text { (Optune, Novocure) }\end{array}$ & $\begin{array}{l}\text { STR, awake } \\
\text { (language, } \\
\text { motor) }\end{array}$ & 2 \\
\hline 3 & $61, \mathrm{M}$ & $\begin{array}{l}\text { GBM, IDH wt, } \\
\text { MGMT m }\end{array}$ & RT & 2 & $\begin{array}{l}\text { Initial surgery STR; RT (preliminarily interrupted due to tumor } \\
\text { progress) + TMZ }\end{array}$ & $\begin{array}{l}\text { STR, IOM } \\
\quad(\text { MEP) }\end{array}$ & 2 \\
\hline 4 & $42, F$ & $\begin{array}{l}\text { GBM, IDH wt, } \\
\text { MGMT m }\end{array}$ & $\mathrm{RP}$ & 17 & $\begin{array}{l}\text { Initial surgery biopsy \& STR; concomitant RT/chemo accord- } \\
\text { ing to Checkmate } 548 \text { protocol; adjuvant chemo according } \\
\text { to Checkmate } 548 \text { protocol, } 6 \text { cycles }\end{array}$ & $\begin{array}{l}\text { STR, IOM } \\
\quad(\text { MEP) }\end{array}$ & 1 \\
\hline 5 & $58, \mathrm{M}$ & $\begin{array}{l}\text { GBM, IDH wt, } \\
\text { MGMT m }\end{array}$ & $\mathrm{RT}$ & 9 & $\begin{array}{l}\text { Initial surgery CR; concomitant RT/chemo (60 Gy) + } \\
\text { Checkmate } 548 \text { protocol; adjuvant chemo according to } \\
\text { Checkmate } 548 \text { protocol, } 6 \text { cycles }\end{array}$ & $\begin{array}{l}\text { CRET, IOM } \\
\quad \text { (VEP) }\end{array}$ & 1 \\
\hline 6 & $55, \mathrm{M}$ & $\begin{array}{l}\text { AO, IDH m, 1p- } \\
19 q \text { codeletion }\end{array}$ & LF & 144 & $\begin{array}{l}\text { Initial surgery biopsy (histology: fibrillary astrocytoma, WHO } \\
\text { grade II); RT w/ } 55 \text { Gy; tumor recurrence: 2nd resection; } \\
\text { RT w/ } 45 \text { Gy }\end{array}$ & CRET & 1 \\
\hline 7 & $48, \mathrm{M}$ & $\begin{array}{l}\text { GBM, IDH wt, } \\
\text { MGMT nm }\end{array}$ & LT & 16 & $\begin{array}{l}\text { Initial surgery CR; concomitant RT/chemo (60 Gy) + TMZ; } \\
\text { TMZ (5/28) } 11 \text { cycles }\end{array}$ & STR & 2 \\
\hline 8 & $68, \mathrm{M}$ & $\begin{array}{l}\text { GBM, IDH wt, } \\
\text { MGMT nm }\end{array}$ & LT & 31 & $\begin{array}{l}\text { Initial surgery CR; concomitant RT/chemo (60 Gy) + TMZ; } \\
\text { TMZ (5/28) } 6 \text { cycles; tumor recurrence: 2nd resection; } \\
\text { PDT of distant lesions; RT } 45 \text { Gy }\end{array}$ & CRET & 1 \\
\hline 9 & $23, F$ & $\begin{array}{l}\text { GBM, IDH wt, } \\
\text { MGMT m }\end{array}$ & RF & 24 & $\begin{array}{l}\text { Initial surgery CR (histology: gliosarcoma); concomitant RT/ } \\
\text { chemo ( } 60 \text { Gy) + TMZ; TMZ (5/28) } 5 \text { cycles; PC } 3 \text { cycles; } \\
\text { methadone }\end{array}$ & STR & 3 \\
\hline 10 & $36, F$ & GBM, IDH wt & RF & 86 & $\begin{array}{l}\text { Initial surgery CR (AA); chemo w/ TMZ; re-resection; con- } \\
\text { comitant RT/chemo (60 Gy) + TMZ; TMZ (5/28) } 14 \text { cycles; } \\
\text { re-resection; concomitant RT/chemo (45 Gy) + TMZ; TMZ } \\
\text { (5/28) } 3 \text { cycles; TTF (Optune, Novocure) }\end{array}$ & $\begin{array}{l}\text { STR, IOM } \\
\quad(\text { MEP) }\end{array}$ & 2 \\
\hline 11 & $21, \mathrm{~F}$ & $\begin{array}{l}\text { GBM, IDH m, } \\
\text { MGMT m }\end{array}$ & RT & 18 & Initial resection CR; high-dose alfacalcidol therapy & STR & 2 \\
\hline 12 & $71, \mathrm{M}$ & $\begin{array}{l}\text { GBM, IDH wt, } \\
\text { MGMT nm }\end{array}$ & LT & 7 & $\begin{array}{l}\text { Initial surgery CR; concomitant RT/chemo (60 Gy) + TMZ; } \\
\text { TMZ (5/28) } 3 \text { cycles }\end{array}$ & $\begin{array}{l}\text { CRET, awake } \\
\text { (language, } \\
\text { motor) }\end{array}$ & 3 \\
\hline 13 & $47, \mathrm{M}$ & $\begin{array}{l}\text { GBM, IDH m, } \\
\text { MGMT m }\end{array}$ & $\mathrm{RP}$ & 64 & $\begin{array}{l}\text { Initial surgery CR (AA); concomitant RT/chemo (60 Gy) + } \\
\text { TMZ; TMZ (5/28) } 6 \text { cycles; re-resection; concomitant RT/ } \\
\text { chemo (30 Gy) + TMZ; TMZ (5/28) } 5 \text { cycles }\end{array}$ & $\begin{array}{l}\text { CRET, IOM } \\
\text { (MEP) }\end{array}$ & 1 \\
\hline 14 & $32, \mathrm{M}$ & $\begin{array}{l}\text { AA, IDH m, } \\
\text { MGMT m }\end{array}$ & LF & 92 & $\begin{array}{l}\text { Initial surgery CR (AA); RT; re-resection; concomitant RT/ } \\
\text { chemo (39.6 Gy) + TMZ; TMZ (5/28) } 6 \text { cycles }\end{array}$ & $\begin{array}{l}\text { CRET, IOM } \\
\quad(\text { MEP) }\end{array}$ & 1 \\
\hline 15 & $63, \mathrm{M}$ & $\begin{array}{l}\text { GBM, IDH wt } \\
\text { (previously), ra- } \\
\text { diation necrosis } \\
\text { (now) }\end{array}$ & LF & 13 & $\begin{array}{l}\text { Initial surgery CR; concomitant RT/chemo (60 Gy) + TMZ; } \\
\text { TMZ (5/28) } 6 \text { cycles }\end{array}$ & $\begin{array}{l}\text { CRET, IOM } \\
\quad(\mathrm{MEP})\end{array}$ & 2 \\
\hline 16 & $55, \mathrm{~F}$ & $\begin{array}{l}\text { GBM, IDH wt, } \\
\text { MGMT nm }\end{array}$ & LF & 9 & $\begin{array}{l}\text { Initial surgery CR; concomitant RT/chemo (60 Gy) + TMZ; } \\
\text { TMZ }(5 / 28) 6 \text { cycles }\end{array}$ & CRET & 2 \\
\hline 17 & $81, \mathrm{~F}$ & $\begin{array}{l}\text { GBM, IDH wt, } \\
\text { MGMT nm }\end{array}$ & RF & 7 & $\begin{array}{l}\text { Initial surgery CR; concomitant RT/chemo (60 Gy) + TMZ; } \\
\text { TMZ (5/28) } 3 \text { cycles }\end{array}$ & STR & 1 \\
\hline 18 & $68, F$ & $\begin{array}{l}\text { GBM, IDH wt, } \\
\text { MGMT nm }\end{array}$ & RF & 5 & $\begin{array}{l}\text { Initial surgery CR; GlioVax Study, randomization in study } \\
\text { arm; concomitant RT/chemo (60 Gy) + TMZ; TMZ (5/28) } \\
2 \text { cycles }\end{array}$ & STR & 1 \\
\hline 19 & $58, \mathrm{M}$ & $\begin{array}{l}\text { GBM, IDH wt, } \\
\text { MGMT m }\end{array}$ & LT & 9 & Concomitant RT/chemo (60 Gy) + TMZ; TMZ (5/28) 3 cycles & STR & 2 \\
\hline
\end{tabular}


» CONTINUED FROM PAGE 430

TABLE 1. Patient characteristics and oncological and surgical details

\begin{tabular}{|c|c|c|c|c|c|c|c|}
\hline $\begin{array}{c}\text { Case } \\
\text { No. }\end{array}$ & $\begin{array}{c}\text { Age (yrs), } \\
\text { Sex }\end{array}$ & Dx & Location* & $\begin{array}{l}\text { Mos Since } \\
\text { Initial Dx }\end{array}$ & Previous Oncological Treatment & Surgery & $\begin{array}{c}\text { No. of } \\
\text { Diffusors }\end{array}$ \\
\hline 20 & $31, \mathrm{M}$ & $\begin{array}{c}\text { GBM, IDH m, } \\
\text { MGMT m }\end{array}$ & RT & 74 & $\begin{array}{l}\text { Initial surgery: CR (diffuse astrocytoma WHO II); RT (59.4 } \\
\text { Gy); re-resection; concomitant RT/chemo (45 Gy) + TMZ; } \\
\text { TMZ (5/28) } 11 \text { cycles }\end{array}$ & CRET & 2 \\
\hline
\end{tabular}

$\mathrm{CCNU}=$ lomustine; $\mathrm{CeTeG}=$ study protocol: CCNU-TMZ combination therapy versus standard TMZ therapy in patients with newly diagnosed GBM with methylated MGMT promoter; chemo = chemotherapy; CR = complete resection; Dx = diagnosis; IDH m = IDH mutated; IDH wt = IDH wild type; IOM = intraoperative monitoring; MGMT $\mathrm{m}=$ MGMT methylated; MGMT $\mathrm{nm}=$ MGMT not methylated; $\mathrm{PC}=$ procarbazine + lomustine; $\mathrm{RT}$ = radiotherapy; TMZ = temozolomide; TTF = tumor-treating fields; VEP = visual-evoked potential.

* Location: $R$ = right, $L=$ left, $F=$ frontal, $P=$ parietal, $T$ = temporal.

$\dagger 5 / 28=$ treatment on 5 of the 28 days.

We defined diffusion restriction as an important efficacy measure. An effect of photodynamic therapy was seen in $80 \%(n=16)$ of our cases. One patient (case 15) was operated on due to the assumption of GBM progression. However, histopathological analysis revealed radiation necrosis without the presence of tumor cells. In this case, no effect of PDT was seen, indicating a high selectivity of this treatment strategy to tumor cells. This high selectivity is supported by a study from Olzowy et al. ${ }^{21}$ who analyzed PDT in a rat model, applying PDT to rats with healthy brain, edematous brain, and GBM. There was no damage in rats with normal brain tissue, mild damage in brains with edema, and a clear effect in rats with GBM, supporting a high selectivity of phototoxic damage.

In the follow-up MR images of our cohort (14 days after surgery), contrast-enhanced attenuation was noted in all patients with an effect of PDT (80\%). CE vanished subsequently over time. In cases of stable disease, $\mathrm{CE}$ vanished almost completely after $4-5$ months.

The efficacy of 5-ALA PDT in HGG has been demonstrated in a limited number of clinical trials. Beck et al. performed a phase I study on patients with recurrent HGG using iPDT, reporting a median survival of 15 months versus an expected survival of 6-8 months. ${ }^{2}$ A further study reported a 56\% 3-year survival rate after iPDT in patients with unresectable newly diagnosed GBMs. ${ }^{26}$

\section{Technical Considerations}

In order to achieve a sufficient treatment effect, several aspects have to be considered when applying oPDT. So far, there is no standardized treatment protocol for oPDT. Some experience is available with 5-ALA PDT used stereotactically. ${ }^{2}$ With this method, a power of $200 \mathrm{~mW} / \mathrm{cm}$ of diffusor length, with a 1-hour illumination period, was not found to elicit adverse events. This results in an energy of $3600 \mathrm{~J} / \mathrm{cm}$ diffusor being delivered to the tumor over a period of 1 hour, an energy that has been found to be without complications in former studies and has been calculated not to cause unwarranted tissue heating in models. ${ }^{27} \mathrm{We}^{2}$ and others ${ }^{22}$ have previously used these power values and timing in the stereotactic setting, i.e., with diffusors being directly embedded in tissue, without irrigation as performed in our present approach. Respective models have demonstrated that given the perfusion and heat dissipation properties of the brain in the stereotactic setting, this light power would serve to elicit a phototoxic effect without harmfully heating the brain. ${ }^{2}$

Overall, protocols for surface irradiation have utilized a fluence of $100-200 \mathrm{~J} / \mathrm{cm}^{2}$, which results in complete photobleaching of PPIX. ${ }^{2}$

With one fiber treating a part of the tumor cavity and assuming that part of the tumor cavity to roughly be a sphere with a diameter of $2 \mathrm{~cm}$, the inner surface would be calculated to approximately equal $12.5 \mathrm{~cm}^{2}$. A $2-\mathrm{cm}$ laser diffusor placed within the cavity would deliver an energy of $7200 \mathrm{~J}$ over 1 hour, resulting in a fluence of $576 / \mathrm{cm}^{2}$ of tissue, thus effectively exceeding the fluence observed to be efficacious in earlier work. ${ }^{2,28}$ In experimental work we have effectively treated spheroids in vitro using a fluence of $25 \mathrm{~J} / \mathrm{cm},{ }^{2,42}$ which resulted in growth arrest with necrosis and apoptosis. We further treated experimental brain tumors in vivo using a fluence of $200 \mathrm{~J} / \mathrm{cm}^{2}$. This resulted in selective tumor death to a depth of at least $3.7 \mathrm{~mm}$ (corresponding to the deepest tumor extension ${ }^{21}$ ). Given the self-limitation of sensitization (sensitizer is bleached away during therapy), we appear to be in an effective therapeutic range with our present laser settings. Significant tissue heating can be ruled out using our approach, whereas phototoxicity would be similar compared to the stereotactic approaches.

Major requirements for successful PDT are homogeneous and sufficient doses of light delivered to the tumor, as the efficacy of PDT is linked to the dose of light irradiance. ${ }^{18,23}$ To achieve this, we continuously irrigated the resection cavity with fluid to inhibit the formation of blood clots and debris that might interfere with laser light reaching targeted tumor cells. In comparison, Dupont et al., in their phase I trial (INDYGO), use a deformable balloon that is inserted into the resection cavity. ${ }^{8}$ However, we believe that blood accumulation at the tumor margins and the balloon itself might attenuate sufficient and homogeneous light penetration, especially in a complex cavity architecture. We are the first to use a multiport high-power laser for the oPDT procedure. This laser provides enough power and distribution of light intensity without the use of additional balloons and filling media. Using our regimen, thermal effects are not expected. Furthermore, overdosing is not possible, because PPIX is subject to degradation depending on the applied irradiance. With complete dissolution of sensitizer, phototoxic- 
TABLE 2. Efficacy analysis of oPDT and resection status after FGR as well as outcome data

\begin{tabular}{|c|c|c|c|c|c|c|c|c|}
\hline $\begin{array}{l}\text { Case } \\
\text { No. }\end{array}$ & Effect & $\begin{array}{l}\text { EOR on } \\
\text { MRI (FGR) }\end{array}$ & $\begin{array}{l}\text { Vol Cytotoxic } \\
\text { Edema }\left(\mathrm{cm}^{3}\right)\end{array}$ & $\begin{array}{l}\text { Penetration } \\
\text { Depth ADC } \\
\text { Signal }(\mathrm{mm})\end{array}$ & Adjuvant Therapy After PDT & $\begin{array}{l}\mathrm{FU} \\
(\mathrm{mos})\end{array}$ & $\begin{array}{l}\text { Disease } \\
\text { Status } \\
\text { (RANO) }\end{array}$ & PDT Area \\
\hline 1 & Yes & STR (STR) & 0.99 & 13.3 & $\begin{array}{l}\text { Concomitant RT/chemo + TMZ, TMZ (5/28) } 8 \\
\text { cycles }\end{array}$ & 9 & PD & $\begin{array}{l}\text { New CE after initial } \\
\text { regression }\end{array}$ \\
\hline 2 & Yes & STR (STR) & 5.61 & 6.5 & $\begin{array}{l}\text { Concomitant RT/chemo + TMZ, depatuxizumab- } \\
\text { mafodotin (ABT-414) + TMZ metronomic, TTF } \\
\text { (Optune, Novocure) }\end{array}$ & 7 & SD & Regression of CE \\
\hline 3 & Yes & STR (STR) & 1.9 & 13.7 & $\begin{array}{l}\text { Concomitant RT/chemo w/ } 36 \text { Gy + TMZ/ } \\
\text { CCNU, TMZ/CCNU } 5 \text { cycles, TTF (Optune, } \\
\text { Novocure) }\end{array}$ & 6 & SD & Regression of CE \\
\hline 4 & No & STR (STR) & No effect & No effect & $\begin{array}{l}\text { Concomitant RT/chemo w/ } 39.6 \text { Gy + TMZ/ } \\
\text { CCNU, TMZ/CCNU } 4 \text { cycles, bevacizumab } \\
1 \text { cycle }\end{array}$ & 7 & PD & Progression of CE \\
\hline 5 & Yes & CRET (CR) & 2.62 & 13.5 & RT & 6 & PD & $\begin{array}{l}\text { No CE, distant tumor } \\
\text { manifestation }\end{array}$ \\
\hline 6 & No & CRET (CR) & No effect & No effect & PCV 2 cycles & 6 & SD & Regression of CE \\
\hline 7 & Yes & STR (STR) & 1.75 & 7.1 & $\begin{array}{l}\text { Concomitant RT/chemo w/ } 39.6 \text { Gy + TMZ/ } \\
\text { CCNU, TMZ/ hydroxyurea } 2 \text { cycles, bevacizu- } \\
\text { mab/irinotecan } 1 \text { cycle }\end{array}$ & 6 & PD & Progression of CE \\
\hline 8 & Yes & CRET (CR) & 3.78 & 7 & CCNU 2 cycles, CV 2 cycles & 6 & PD & Progression of CE \\
\hline 9 & Yes & STR (STR) & 7.89 & 9.7 & Best supportive care & 2 & PD & Progression of CE \\
\hline 10 & Yes & STR (STR) & 8.4 & 8.4 & CCNU 4 cycles & 5 & PD & $\begin{array}{l}\text { Stable } \mathrm{CE} \text {, distant } \\
\text { tumor progression }\end{array}$ \\
\hline 11 & Yes & STR (CR) & 0.89 & 5 & $\begin{array}{l}\text { Concomitant RT/chemo + TMZ, TMZ (5/28) } 4 \\
\text { cycles }\end{array}$ & 6 & SD & No CE \\
\hline 12 & Yes & CRET (STR) & 6.74 & 4.1 & Best supportive care & 1 & PD & $\begin{array}{l}\text { Distant tumor mani- } \\
\text { festation, regres- } \\
\text { sion of CE at site } \\
\text { of PDT }\end{array}$ \\
\hline 13 & Yes & CRET (CR) & 2.56 & 8.9 & PCV 4 Cy, TTF (Optune, Novocure) & 5 & SD & Regression of CE \\
\hline 14 & Yes & CRET (STR) & 3.78 & 9.8 & TMZ 1 wk on/1 wk off & 3 & SD & Regression of CE \\
\hline 15 & No & CRET (CR) & No effect & No effect & Wait \& see & 4 & SD & No CE \\
\hline 16 & Yes & CRET (CR) & 0.71 & 11.8 & Concomitant RT/chemo w/ $30 \mathrm{~Gy}+\mathrm{TMZ}$ & 3 & PD & $\begin{array}{l}\text { New CE after initial } \\
\text { regression }\end{array}$ \\
\hline 17 & Yes & STR (STR) & 3.22 & 10 & Best supportive care & 2 & PD & CE \\
\hline 18 & Yes & STR (STR) & 1.94 & 5.6 & None (due to hip trauma), CCNU 1 cycle & 3 & PD & $\mathrm{CE}$ \\
\hline 19 & Yes & STR (STR) & 0.48 & 11.2 & Concomitant RT/chemo w/ 34.2 Gy + CCNU & 1 & SD & No CE \\
\hline 20 & No & CRET (CR) & No effect & No effect & CCNU/TMZ 3 cycles & 3 & PD & $\begin{array}{l}\text { New CE after initial } \\
\text { regression }\end{array}$ \\
\hline
\end{tabular}

$\mathrm{CV}=$ lomustine and vincristine; $\mathrm{FU}$ = follow-up; $\mathrm{PCV}=$ procarbazine, lomustine, and vincristine $; \mathrm{PD}$ = progressive disease; $\mathrm{SD}=$ stable disease .

ity terminates. Prolonged laser irradiation will not lead to further phototoxic effects, and normal brain cells, which do not accumulate PPIX, will not be affected by this procedure. ${ }^{27}$ This principle enables the use of 5-ALAinduced oPDT even in areas close to or within eloquent regions.

Penetration depth, measured via diffusion signal changes around the resection cavity, varied between 4.1 and 13.7 $\mathrm{mm}$ in our cohort. Wang et al. ${ }^{39}$ reported substantial interpatient heterogeneity in penetration depth after intraperitoneal PDT. The authors hold effects such as photobleaching, variable amounts of oxygenation, concentration of photosensitizer in the cell, and tissue properties responsible for these variations. In general, for wavelengths between 625 and $640 \mathrm{~nm}$, a biologically effective penetration depth of $0.8-1 \mathrm{~cm}$ has been described in iPDT ${ }^{23}$ In oPDT we could demonstrate higher effective penetration depths in individual cases.

The main effect of tissue damage triggered by PDT is based on the creation of reactive oxygen species. Therefore, high tissue concentrations of molecular oxygen are required to increase effects during therapy. ${ }^{3}$ To provide this, our patients underwent ventilation with $100 \%$ oxygen throughout the PDT. 


\section{A PreOP FLAIR PreOP T1Gd 48h postOP ADC Map}
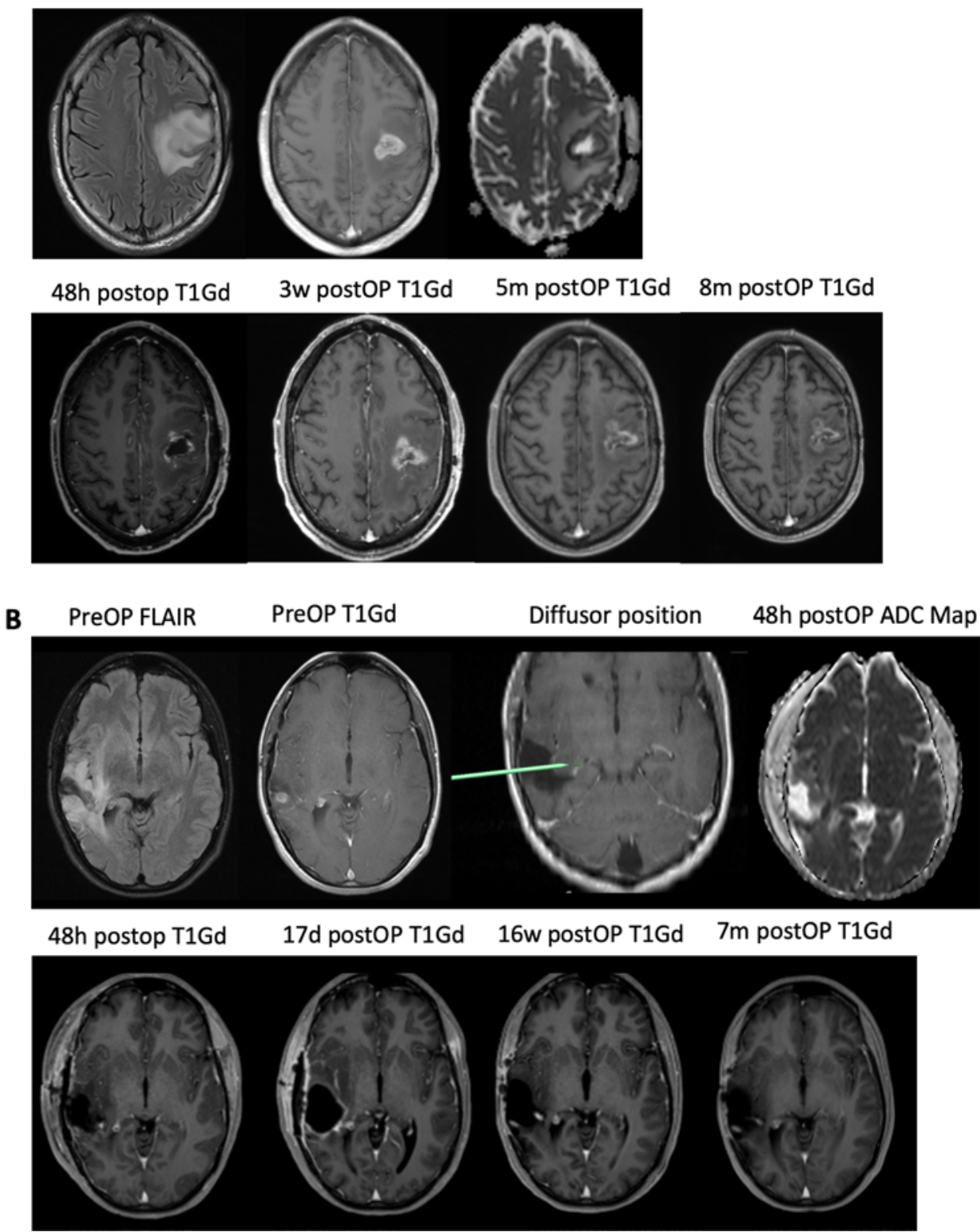

FIG. 2. A: Case 2. Axial MR images obtained in a 41-year-old man with recurrent GBM (IDH wildtype, MGMT not methylated) in the left central region. After tumor resection under awake conditions open PDT was performed with 2 diffusors. Early postoperative MRI revealed annular cytotoxic edema around the resection cavity in regions of remaining tumor. Follow-up MRI showed progressive $\mathrm{CE}$ in the edema region, vanishing after 5 months without any signs of tumor progression. B: Case 11. Axial MR images obtained in a 21-year-old woman with recurrent GBM (IDH mutated, MGMT methylated) in the right temporal region. After tumor resection, open PDT was performed with 2 diffusors. Early postoperative MRI revealed cytotoxic edema to the optic radiation according to the position of the diffusor. Follow-up MRI showed CE in this region, vanishing after 16 weeks without any signs of tumor progression in further follow-up imaging. Figure is available in color online only.

\section{Safety of the Procedure}

Higher rates of complications are reported in recurrent glioma surgery when compared to surgery for initially diagnosed glioma. ${ }^{13}$ With this in mind, our analysis also focused on the safety of repeat FGR in combination with oPDT. Fortunately, we only observed 1 case of surgical site infection, which did not manifest before 6 months after surgery under second-line chemotherapy with bevaciz- umab. We are unsure that this surgical site infection can be directly attributed to our treatment and may be related to antiangiogenic treatment.

Although oPDT addresses the infiltration zone possibly containing motor function or speech eloquence, the high selectivity of destruction of tumor cells only did not cause any additional neurological deficits. In addition, no mortality directly associated with FGR or oPDT was ob- 

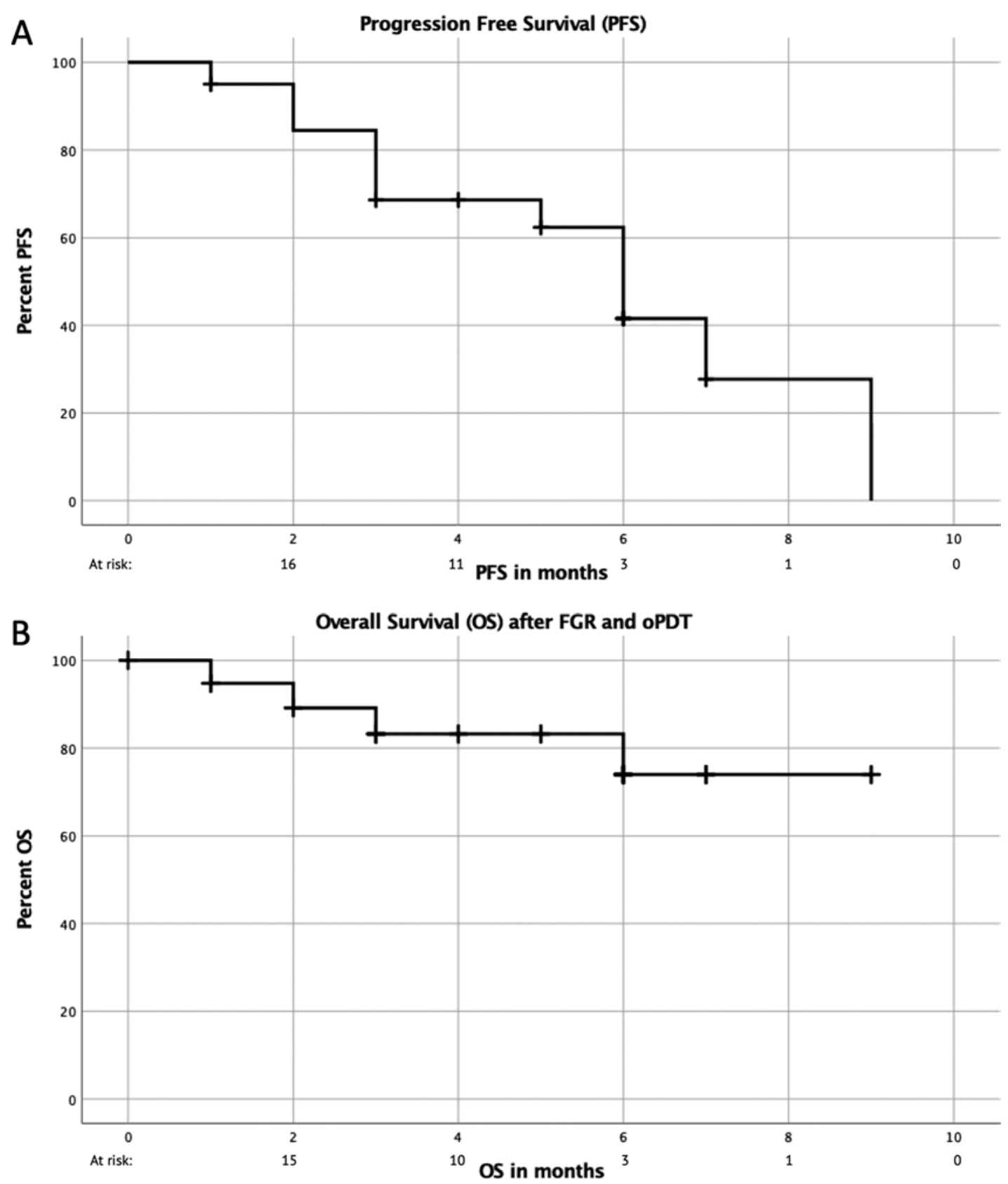

FIG. 3. A: Kaplan-Meier curve of PFS after FGR and oPDT. B: Kaplan-Meier curve of OS after FGR and oPDT. + = censored.

served. No adverse events from administration of 5-ALA occurred. Consequently, this dual approach appears to carry a low risk.

\section{Open PDT in Combination With Adjuvant Treatment and Impact on Survival}

Despite the fact that we also included patients with second tumor recurrence that have utilized almost all current treatment options, these patients still showed favorable PFS in our series compared to other studies. ${ }^{37}$ However, it remains challenging to compare our survival outcomes to other studies due to the heterogeneity of our collective and the lack of prospective and randomized controlled studies to confirm the benefit of re-resection..$^{5}$ The type and number of previous oncological therapies does not appear to have an influence on the response to PDT, making PDT a feasible therapy option in patients with recurrent HGG lacking further treatment options. This aspect has also been demonstrated in other studies. ${ }^{35,41}$

\section{Strengths and Limitations of the Study}

To the best of our knowledge, this is the first study reporting outcomes and efficacy after FGR and 5-ALAinduced oPDT in patients with recurrent HGG, showing 
promising results and the first report of the use of a multiple-fiber technique with intraoperative irrigation. There are some limitations that merit mention, foremost the study's retrospective design. However, electronic medical records and sufficient follow-up data helped enormously with retrospective analysis and proved highly reliable. The heterogenic patient spectrum in terms of molecular tumor subtypes and variable adjuvant treatment concepts complicate survival analysis and assessment of the real effect of PDT on outcome. It remains challenging to measure the effects of PDT on postoperative MRI, as diffusion signaling changes similar to postoperative infarction. A sham/ blinded experimental study would be interesting. However, we routinely perform early postoperative MRI in all patients after FGR; the described phenomenon after oPDT has never been recognized in any patient without additional oPDT. At this stage, we cannot prove that the enhancing regions seen later on postoperative MRI are specific and the result of oPDT. Still, we believe that the novelty of our encouraging data deserves mention.

\section{Future Directions}

Further studies are needed to evaluate long-term effects of PDT, especially concerning local and systemic immune responses and synergies with adjuvant treatments. In addition, there are some procedural aspects that need further investigation, such as the assessment of light intensity, light delivery protocols, dosimetry, the different PPIX concentrations in the treated tumor areas and their influence on the efficacy of PDT, and objective measurement of the PDT effect in postoperative MRI. Further important aspects are the number and position of diffusors, duration and dosage of applied PDT, and possible interface effects between irrigation fluid and the resection cavity surface.

\section{Conclusions}

Combined FGR and 5-ALA-induced oPDT provides an innovative and safe method of further local tumor treatment, fulfilling the need for targeted tumor treatment. A major advantage of PDT is that it can be used in addition to standard-of-care treatment concepts. Furthermore, the possibility to perform 5-ALA FGR and PDT at the same time with the same dose of drug administered should not be underestimated. In some tumor cells fluorescence is not visible due to lower cell density. However, these cells are photosensitized as well and addressed by oPDT. Additional oPDT to resection of fluorescent tumor enables the creation of a safety margin or treatment of nonresectable tumor in eloquent regions. At the same time, due to its high selectivity to malignant cells, PDT spares unaffected brain regions. This method might be eligible for first-line therapy as well and is currently being investigated in a prospective trial. The use of a high-power laser, enabling light diffusion even in complex resection cavities without the use of additional devices such as balloons filled with light-distributing media, in combination with the second-generation glioma-specific photosensitizer 5-ALA, show promising advantages of this former investigated approach. Multicenter, controlled, randomized phase III trials are warranted to evaluate longterm effects of FGS with oPDT regarding OS and PFS.

\section{Acknowledgments}

Dr. Schipmann acknowledges the Medical Faculty of the Westphalian Wilhelms-University of Münster for their support.

\section{References}

1. Au CM, Luk SK, Jackson CJ, Ng HK, Yow CM, To SS: Differential effects of photofrin, 5-aminolevulinic acid and calphostin C on glioma cells. J Photochem Photobiol B 85:92-101, 2006

2. Beck TJ, Kreth FW, Beyer W, Mehrkens JH, Obermeier A, Stepp H, et al: Interstitial photodynamic therapy of nonresectable malignant glioma recurrences using 5-aminolevulinic acid induced protoporphyrin IX. Lasers Surg Med 39:386-393, 2007

3. Castano AP, Demidova TN, Hamblin MR: Mechanisms in photodynamic therapy: part two-cellular signaling, cell metabolism and modes of cell death. Photodiagn Photodyn Ther 2:1-23, 2005

4. Chaichana KL, Zadnik P, Weingart JD, Olivi A, Gallia GL, Blakeley J, et al: Multiple resections for patients with glioblastoma: prolonging survival. J Neurosurg 118:812-820, 2013

5. Chaul-Barbosa C, Marques DF: How we treat recurrent glioblastoma today and current evidence. Curr Oncol Rep 21:94, 2019

6. Chilakamarthi U, Giribabu L: Photodynamic therapy: past, present and future. Chem Rec 17:775-802, 2017

7. Desjardins A, Gromeier M, Herndon JE II, Beaubier N, Bolognesi DP, Friedman AH, et al: Recurrent glioblastoma treated with recombinant poliovirus. N Engl J Med 379:150-161, 2018

8. Dupont C, Vermandel M, Leroy HA, Quidet M, Lecomte F, Delhem N, et al: INtraoperative photoDYnamic Therapy for GliOblastomas (INDYGO): study protocol for a phase I clinical trial. Neurosurgery 84:E414-E419, 2019

9. Etminan N, Peters C, Lakbir D, Bünemann E, Börger V, Sabel MC, et al: Heat-shock protein 70-dependent dendritic cell activation by 5 -aminolevulinic acid-mediated photodynamic treatment of human glioblastoma spheroids in vitro. $\mathbf{B r} \mathbf{J}$ Cancer 105:961-969, 2011

10. Gilbert MR, Dignam JJ, Armstrong TS, Wefel JS, Blumenthal DT, Vogelbaum MA, et al: A randomized trial of bevacizumab for newly diagnosed glioblastoma. N Engl J Med 370:699-708, 2014

11. Henderson BW, Dougherty TJ: How does photodynamic therapy work? Photochem Photobiol 55:145-157, 1992

12. Hickmann AK, Nadji-Ohl M, Hopf NJ: Feasibility of fluorescence-guided resection of recurrent gliomas using five-aminolevulinic acid: retrospective analysis of surgical and neurological outcome in 58 patients. J Neurooncol 122:151-160, 2015

13. Hoover JM, Nwojo M, Puffer R, Mandrekar J, Meyer FB, Parney IF: Surgical outcomes in recurrent glioma: clinical article. J Neurosurg 118:1224-1231, 2013

14. Johansson A, Faber F, Kniebühler G, Stepp H, Sroka R, Egensperger R, et al: Protoporphyrin IX fluorescence and photobleaching during interstitial photodynamic therapy of malignant gliomas for early treatment prognosis. Lasers Surg Med 45:225-234, 2013

15. Kennedy JC, Pottier RH, Pross DC: Photodynamic therapy with endogenous protoporphyrin IX: basic principles and present clinical experience. J Photochem Photobiol B 6:143-148, 1990

16. Kessel D: Apoptosis, paraptosis and autophagy: death and survival pathways associated with photodynamic therapy. Photochem Photobiol 95:119-125, 2019

17. Li F, Cheng Y, Lu J, Hu R, Wan Q, Feng H: Photodynamic therapy boosts anti-glioma immunity in mice: a dependence 
on the activities of T cells and complement C3. J Cell Biochem 112:3035-3043, 2011

18. Mang TS: Dosimetric concepts for PDT. Photodiagn Photodyn Ther 5:217-223, 2008

19. Muller PJ, Wilson BC: Photodynamic therapy of brain tumors-a work in progress. Lasers Surg Med 38:384-389, 2006

20. Muller PJ, Wilson BC: A randomized two arm clinical trial of photophrin PDT and standard therapy in high grade gliomas-phase III trial, in Proceedings of the 6th International Symposium on Photodynamic Diagnosis and Therapy in Clinical Practice. Brixen/Bressanone, Italy, October 10-14, 2006

21. Olzowy B, Hundt CS, Stocker S, Bise K, Reulen HJ, Stummer W: Photoirradiation therapy of experimental malignant glioma with 5-aminolevulinic acid. J Neurosurg 97:970976,2002

22. Powers SK, Cush SS, Walstad DL, Kwock L: Stereotactic intratumoral photodynamic therapy for recurrent malignant brain tumors. Neurosurgery 29:688-696, 1991

23. Quirk BJ, Brandal G, Donlon S, Vera JC, Mang TS, Foy AB, et al: Photodynamic therapy (PDT) for malignant brain tumors-where do we stand? Photodiagn Photodyn Ther 12:530-544, 2015

24. Ringel F, Pape H, Sabel M, Krex D, Bock HC, Misch M, et al: Clinical benefit from resection of recurrent glioblastomas: results of a multicenter study including 503 patients with recurrent glioblastomas undergoing surgical resection. Neuro Oncol 18:96-104, 2016

25. Schroeteler J, Grauer O, Ewelt C, Wölfer J, Schipmann S, Schwake M, et al: Controlled clinical trial to evaluate the safety and efficacy of stereotactical photodynamic therapy with 5-amino-levulinic acid (Gliolan) in recurrent glioblastoma-an introduction. The 68th Annual Meeting of the German Society of Neurosurgery, Magdeburg, Germany, May 14-17, 2017 (https://www.egms.de/static/en/meetings/ dgnc2017/17dgnc192.shtml) [Accessed December 5, 2019]

26. Schwartz C, Rühm A, Tonn JC, Kreth S, Kreth FW: Surg-25: Interstitial photodynamic therapy of de-novo glioblastoma multiforme WHO IV. Neuro Oncol 17 (Suppl 5):v219-v220, 2015

27. Stepp H, Stummer W: 5-ALA in the management of malignant glioma. Lasers Surg Med 50:399-419, 2018

28. Stummer W, Beck T, Beyer W, Mehrkens JH, Obermeier A, Etminan N, et al: Long-sustaining response in a patient with non-resectable, distant recurrence of glioblastoma multiforme treated by interstitial photodynamic therapy using 5-ALA: case report. J Neurooncol 87:103-109, 2008

29. Stummer W, Götz C, Hassan A, Heimann A, Kempski O: Kinetics of Photofrin II in perifocal brain edema. Neurosurgery 33:1075-1082, 1993

30. Stummer W, Pichlmeier U, Meinel T, Wiestler OD, Zanella F, Reulen HJ: Fluorescence-guided surgery with 5-aminolevulinic acid for resection of malignant glioma: a randomised controlled multicentre phase III trial. Lancet Oncol 7:392401, 2006

31. Stummer W, Stepp H, Möller G, Ehrhardt A, Leonhard M, Reulen HJ: Technical principles for protoporphyrin-IX-fluorescence guided microsurgical resection of malignant glioma tissue. Acta Neurochir (Wien) 140:995-1000, 1998

32. Stummer W, Stepp H, Wiestler OD, Pichlmeier U: Randomized, prospective double-blinded study comparing 3 different doses of 5-aminolevulinic acid for fluorescence-guided resections of malignant gliomas. Neurosurgery 81:230-239, 2017

33. Stummer W, Tonn JC, Goetz C, Ullrich W, Stepp H, Bink A, et al: 5-Aminolevulinic acid-derived tumor fluorescence: the diagnostic accuracy of visible fluorescence qualities as corroborated by spectrometry and histology and postoperative imaging. Neurosurgery 74:310-320, 2014
34. Stupp R, Mason WP, van den Bent MJ, Weller M, Fisher $\mathrm{B}$, Taphoorn MJ, et al: Radiotherapy plus concomitant and adjuvant temozolomide for glioblastoma. N Engl J Med 352:987-996, 2005

35. Stylli SS, Kaye AH, MacGregor L, Howes M, Rajendra P: Photodynamic therapy of high grade glioma-long term survival. J Clin Neurosci 12:389-398, 2005

36. Valdés PA, Leblond F, Kim A, Harris BT, Wilson BC, Fan $\mathrm{X}$, et al: Quantitative fluorescence in intracranial tumor: implications for ALA-induced PpIX as an intraoperative biomarker. J Neurosurg 115:11-17, 2011

37. van Linde ME, Brahm CG, de Witt Hamer PC, Reijneveld JC, Bruynzeel AME, Vandertop WP, et al: Treatment outcome of patients with recurrent glioblastoma multiforme: a retrospective multicenter analysis. J Neurooncol 135:183192, 2017

38. Wallner KE, Galicich JH, Krol G, Arbit E, Malkin MG: Patterns of failure following treatment for glioblastoma multiforme and anaplastic astrocytoma. Int J Radiat Oncol Biol Phys 16:1405-1409, 1989

39. Wang HW, Zhu TC, Putt ME, Solonenko M, Metz J, Dimofte A, et al: Broadband reflectance measurements of light penetration, blood oxygenation, hemoglobin concentration, and drug concentration in human intraperitoneal tissues before and after photodynamic therapy. J Biomed Opt 10:14004, 2005

40. Wen PY, Macdonald DR, Reardon DA, Cloughesy TF, Sorensen AG, Galanis E, et al: Updated response assessment criteria for high-grade gliomas: response assessment in neurooncology working group. J Clin Oncol 28:1963-1972, 2010

41. Wong ET, Hess KR, Gleason MJ, Jaeckle KA, Kyritsis AP, Prados MD, et al: Outcomes and prognostic factors in recurrent glioma patients enrolled onto phase II clinical trials. J Clin Oncol 17:2572-2578, 1999

42. Zelenkov P, Baumgartner R, Bise K, Heide M, Meier R, Stocker S, et al: Acute morphological sequelae of photodynamic therapy with 5-aminolevulinic acid in the C6 spheroid model. J Neurooncol 82:49-60, 2007

\section{Disclosures}

Dr. Stummer reports consultant and lecture activities for Carl Zeiss Meditech, Photonamic, Medac, and NXDC.

\section{Author Contributions}

Conception and design: Warneke, Stummer. Acquisition of data: Schipmann, Müther, Stögbauer, Brokinkel, Holling, Grauer, Suero Molina. Analysis and interpretation of data: Schipmann, Müther, Stögbauer, Zimmer, Brokinkel, Holling, Grauer, Warneke. Drafting the article: Schipmann, Müther. Critically revising the article: Müther, Suero Molina, Stummer. Reviewed submitted version of manuscript: Müther. Approved the final version of the manuscript on behalf of all authors: Schipmann. Statistical analysis: Schipmann. Administrative/technical/material support: Warneke, Stummer. Study supervision: Warneke, Stummer.

\section{Supplemental Information}

\section{Previous Presentations}

Portions of this work were presented in abstract form at the Annual Meeting of the German Society of Neurosurgery (DGNC), May 2019, in Würzburg, Germany.

\section{Correspondence}

Stephanie Schipmann: University Hospital Münster, Germany. stephanie.schipmann@ukmuenster.de. 